\title{
Direct Synthesis of 5-Hydroxymethylfurfural (HMF) from Cellulose using Saturated Steam
}

\author{
Seiichiro YoshidA $^{1^{*}}$, Keiichiro MATSUSHIMA ${ }^{1}$, and Tohru JobOJI ${ }^{2}$ \\ ${ }^{1}$ Industrial Research Institute, Industrial Technology Research Department, Hokkaido Research Organization, N19W11, Kita-ku, \\ Sapporo, Hokkaido 060-0819, Japan \\ ${ }^{2}$ IMRA JAPAN CO., LTD., Techno-Park 2-3-6 Shimonopporo, Atsubetsu-ku, Sapporo, Hokkaido 004-0015, Japan
}

\begin{abstract}
Hydroxymethylfurfural (HMF), a compound that can be synthesized from cellulose, has attracted significant attention because it can be converted into various chemical products. Although various methods for the direct conversion of cellulose to HMF using special solvents and catalysts have been reported, they are not desirable in terms of green sustainable chemistry and manufacturing costs. Herein, we report the direct conversion of cellulose to HMF using saturated steam, i.e., water, as an environment-friendly method. We investigated the effects of the molecular weight of cellulose and amount of added water on the yields of glucose and HMF using a batch system. Glucose and HMF yields were improved by using low-molecular-weight cellulose as the raw material and the amount of added water was important for maximizing the HMF yield. The balance of hydrolysis and dehydration was controlled by optimizing the amount of added water, with a maximized HMF yields of $21 \%$. This study demonstrates that saturated steam has great potential to be applied for the direct conversion of cellulose to HMF.
\end{abstract}

\section{Introduction}

The modern society is based on oil refineries, which produce many chemical products from petroleum. However, due to potential exhaustion of petroleum resources and instability of their supply, use of a "biorefinery", which synthesizes chemical products from biomass instead of petroleum, is desired. Therefore, various studies have attempted to convert cellulose, a plant biomass with extremely large reserves, into various chemical products. Among the useful chemical products obtained from cellulose, 5-hydroxymethyl furfural (HMF) has been actively studied because it can be subsequently converted to chemical products such as fuels, polymers, and pharmaceuticals (Rosatella et al., 2011).

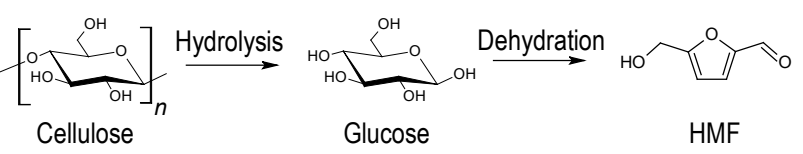

Scheme 1 The conversion of cellulose to HMF

Scheme 1 shows a sequential reaction scheme of the conversation of cellulose to HMF. From this reaction scheme, it is clear that to synthesize HMF from cellulose, hydrolysis of cellulose to glucose and subsequent dehydration of glucose to HMF is necessary. Therefore, conversion of cellulose to HMF in one-pot is challenging. Various reports related to the direct conversion of cellulose to HMF have been published. For example, direct conversion of cellulose to HMF via metal chloride catalysis in ionic liquids, acid-base catalysts in ionic liquids, as well as Brønsted acids and metal chloride catalysts in N,N-dimethylacetamide (DMA) with lithium chloride ( $\mathrm{LiCl})$ have been reported (Kim et al., 2011; Peng et al., 2012; Binder and Raines, 2009). However, in these studies, special solvents, including ionic liquids, and metal catalysts are required. In terms of green sustainable chemistry, these processes are problematic because ionic liquids are expensive and metal catalysts can be harmful to the environment.

In contrast, it has been found that water under hightemperature and high-pressure, i.e. subcritical and supercritical water, can facilitate the hydrolysis and dehydration condensation of saccharides (Kabyemela et al., 1997; Kabyemela et al., 1998; Kabyemela et al., 1999). Because these reactions are facilitated using only water, it is preferable in terms of green sustainable chemistry. However, undesirable side reactions such as HMF hydrolysis, which occur simultaneously under severe reaction conditions, have limited the HMF yield.

To overcome this issue, we used saturated steam, which is milder than high-pressure high-temperature water, to effectively convert cellulose to HMF. Dehydration could be efficiently achieved while suppressing side reactions using saturated steam wherein gas and liquid coexist. Herein, we aimed to convert cellulose to HMF using a one-pot conversion in a batch reaction system. We investigated the effects of the molecular weight of cellulose and amount of water added on the yields of glucose and HMF.

\footnotetext{
* Corresponding author: yoshida-seiichiro@hro.or.jp
} 


\subsection{Materials}

Microcrystalline cellulose was purchased from Merck, Germany. Glucose and HMF were purchased from Fujifilm Wako Pure Chemical Corporation, Japan. Microcrystalline cellulose was treated with a tandem ring mill for $6 \mathrm{~h}$ at $1600 \mathrm{rpm}$ at $200^{\circ} \mathrm{C}$ to obtain low molecular weight cellulose (Shiraishi et al., 2014).

\subsection{Conversion of cellulose to HMF}

Specific amounts of cellulose and double deionized water were added to a stainless steel (SUS) tube (inner volume of $10 \mathrm{~cm}^{3}$ ). The amount of added water was defined by the ratio of of water $(\mathrm{W}(\mathrm{mol}))$ to glucose units in cellulose $(\mathrm{G}(\mathrm{mol}))(\mathrm{W} / \mathrm{G}(\mathrm{mol} / \mathrm{mol}))$. The sample loaded tube was placed in an oil bath maintained at $200^{\circ} \mathrm{C}$ and heated for a specific time. The tube was removed from the bath and placed in an ice bath to quench the reaction. After cooling the tube, the sample was removed from the tube and the inside of the tube was washed with double deionized water to remove the sample. The concentration of HMF and glucose in the obtained solution was measured using a high-performance liquid chromatography (HPLC) system (Chromaseter 5210, Hitachi High-Technologies Corporation, Japan). The glucose concentration was measured using an HPX-87P (Bio-Rad Laboratories, Inc., USA) instrument connected to a refractive index (RI) detector using water as the eluent. The HMF concentration was also measured using HPX-87H (BioRad Laboratories, Inc., USA) connected to an ultravioletvisible (UV-vis) detector with $5 \mathrm{mmol} / \mathrm{L}$ sulfuric acid as the eluent. The temperatures of both columns were maintained at $55^{\circ} \mathrm{C}$ and the flow rates of both eluents were $0.6 \mathrm{~mL} / \mathrm{min}$

\section{Results and Discussion}

\subsection{The effect of the molecular weight of cellulose on HMF conversion}

First, commercially available microcrystalline cellulose was reacted under saturated steam conditions to determine whether glucose and HMF would form (Figure 1). At 30 to $60 \mathrm{~min}$ from the start of the reaction, almost no HMF was produced $(<1 \%)$, but marginal glucose production was confirmed $(\sim 3 \%)$. Afterwards, the glucose production increased and reached at maximum at approximately $8 \%$, but subsequently decreased. In contrast, the yield of HMF gradually increased, reaching a maximum yield of approximately $8 \%$ in $240 \mathrm{~min}$. From this result, it was confirmed that the hydrolysis of cellulose to form glucose occurred initially and the sequential dehydration of glucose to HMF occurred.

Subsequently, the same reaction was performed under saturated steam conditions on cellulose subjected to molecular weight reduction treatment (low molecular weight cellulose) (Figure 2). The yields of glucose and HMF improved when compared to using microcrystalline cellulose. The yield of glucose reached approximately $35 \%$ after 15 to $30 \mathrm{~min}$, and thereafter the yield was approximately $0 \%$. In addition, the yield of HMF reached a maximum of approximately $19 \%$. This improved yield can be explained by differences in the molecular weights of the cellulose samples. On the other hand, HMF yield decreased after $60 \mathrm{~min}$. It was observed that film-like residues formed after $60 \mathrm{~min}$ reaction. This observation indicates that HMF might be polymerized under the saturated steam condition. The degree of polymerization of the microcrystalline and low molecular weight celluloses were 231 and 32, respectively. Therefore, glucose was rapidly generated and converted to HMF. In

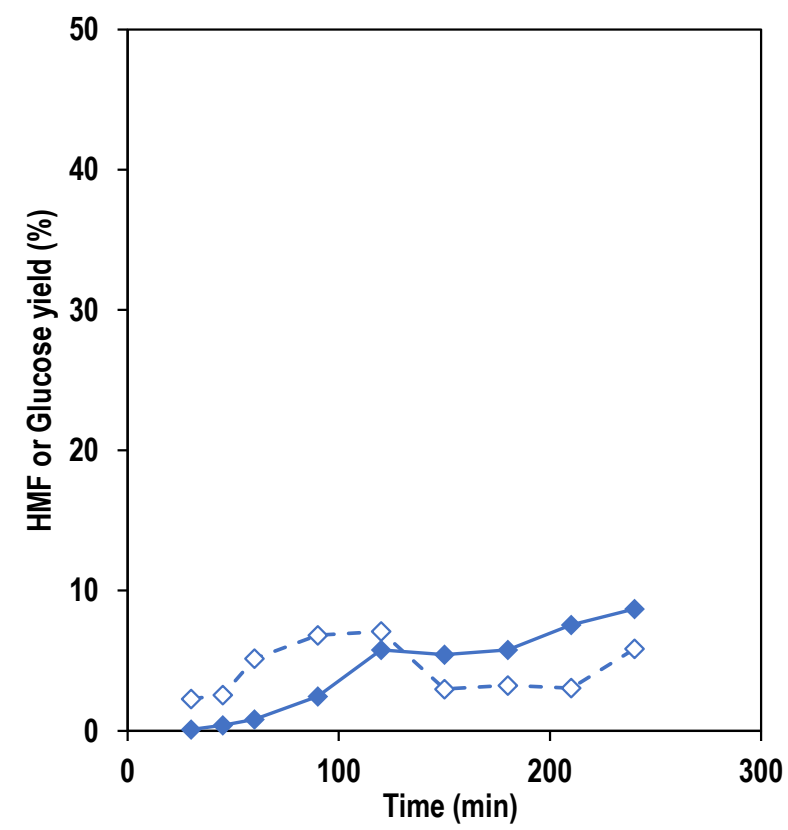

Figure 1 Time course of glucose (open rhombus) and HMF (closed rhombus) yield using microcrystalline cellulose as a raw material $\left(200{ }^{\circ} \mathrm{C}, \mathrm{W} / \mathrm{G}=123\right)$

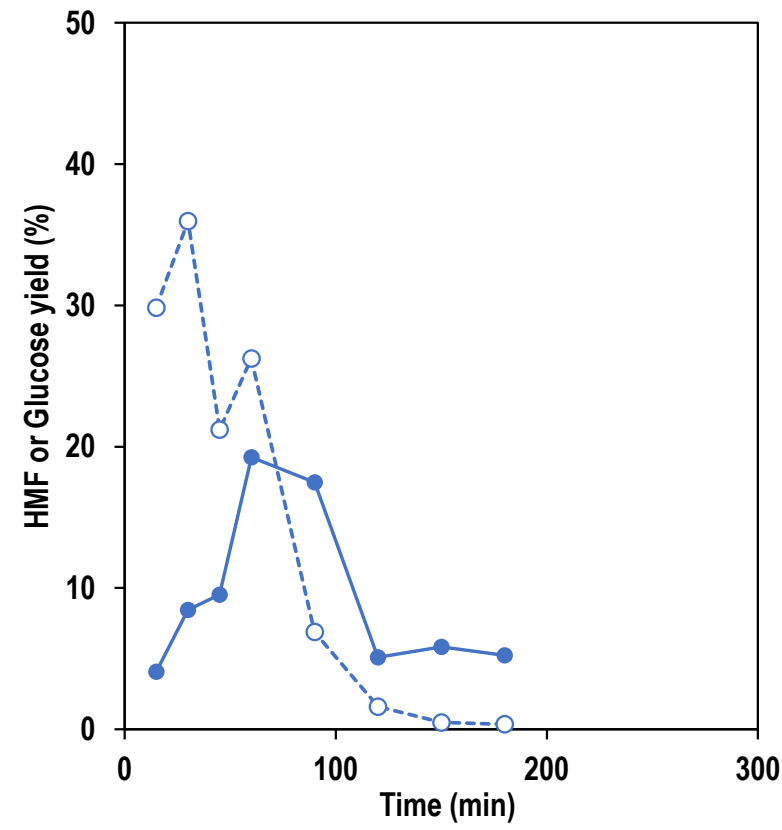

Figure 2 Time course of glucose (open circle) and HMF (closed circle) yields using low molecular 
weight cellulose as a raw material $\left(200^{\circ} \mathrm{C}\right.$, $\mathrm{W} / \mathrm{G}=123$ )

addition, the low molecular weight cellulose as a raw material contained $\leq 1 \%$ glucose. This result shows that the production of glucose via hydrolysis of cellulose and production of HMF via dehydration of glucose occur sequentially. In addition, for microcrystalline cellulose, the yield of glucose increased gradually because hydrolysis proceeded only partially in the amorphous region of the cellulose. Thus, the HMF yield was lower compared with the low molecular weight cellulose.

\subsection{The effect of added water on HMF conversion}

In the previous section, cellulose was converted to HMF under saturated steam conditions. As mentioned in the introduction, the conversion from cellulose to glucose and glucose to HMF is a sequential reaction of hydrolysis and dehydration, respectively. Thus, it was predicted that the water content would affect the HMF yield. To evaluate the influence of the water content on the reaction, the experiment was performed using various molar ratios of water $(\mathrm{W}(\mathrm{mol}))$ to glucose units in cellulose $(\mathrm{G}(\mathrm{mol}))$ $(\mathrm{W} / \mathrm{G})$. Low molecular weight cellulose was used as the raw starting material. The time course of the glucose and $\mathrm{HMF}$ yields with various $\mathrm{W} / \mathrm{G}$ ratios are shown in Figures 3 and 4, respectively. Although no dramatic differences in the time course of the glucose yield were observed. When the $\mathrm{W} / \mathrm{G}$ values was large, glucose was generated over a longer time likely because the generation of glucose by hydrolysis of cellulose occurs when the water content is higher. In contrast, the HMF yield was clearly affected by the water content. Although the HMF yield was approximately $9 \%$ when $\mathrm{W} / \mathrm{G}=50$, the yield increased $21 \%$ at $\mathrm{W} / \mathrm{G}=130$. When $\mathrm{W} / \mathrm{G}$ was further increased to 150 , the yield decreased to $15 \%$. These results can be explained by the difference in the ratio of the water phase present in the reaction vessel. It is thought that both liquid and gas phase water coexist in the reaction vessel in these $\mathrm{W} / \mathrm{G}$ ratio. When the $\mathrm{W} / \mathrm{G}$ ratio is large, liquid water is abundant in the system. Therefore, it is considered that cellulose easily undergoes hydrolysis. On the other hand, when the $W / G$ ratio is small, steam is abundant in the system. Thus, it is considered that the dehydration of glucose is likely to proceed. Plotting the yield of HMF at $60 \mathrm{~min}$ against the value of $\mathrm{W} / \mathrm{G}$ showed a maximum point (Figure 5), indicating that dehydration is dominant in at $\mathrm{W} / \mathrm{G}$ of $<130$. In contrast, hydrolysis was dominant at $\mathrm{W} / \mathrm{G}$ values of $>130$. Therefore, the generated HMF was shown to rapidly decompose in this region. The obtained results indicated that the water content at $\mathrm{W} / \mathrm{G}=$ 130 balances the hydrolysis and dehydration to maximize the HMF yield under the conditions used herein.

\section{Conclusion}

Herein, we reported the direct conversion of cellulose to HMF using saturated steam. The process of reducing the molecular weight of cellulose improved the glucose and HMF yields and an optimal water content can maximize the HMF yield. The obtained results indicated that HMF can be synthesized directly from cellulose via saturated steam, i.e. only water. Because the pressure of saturated steam is lower than that of subcritical and supercritical water, a pressure container may not be necessary, resulting in lower manufacturing costs. This study indicates that saturated steam has the potential to be applied for various chemical reactions including hydration and dehydration.

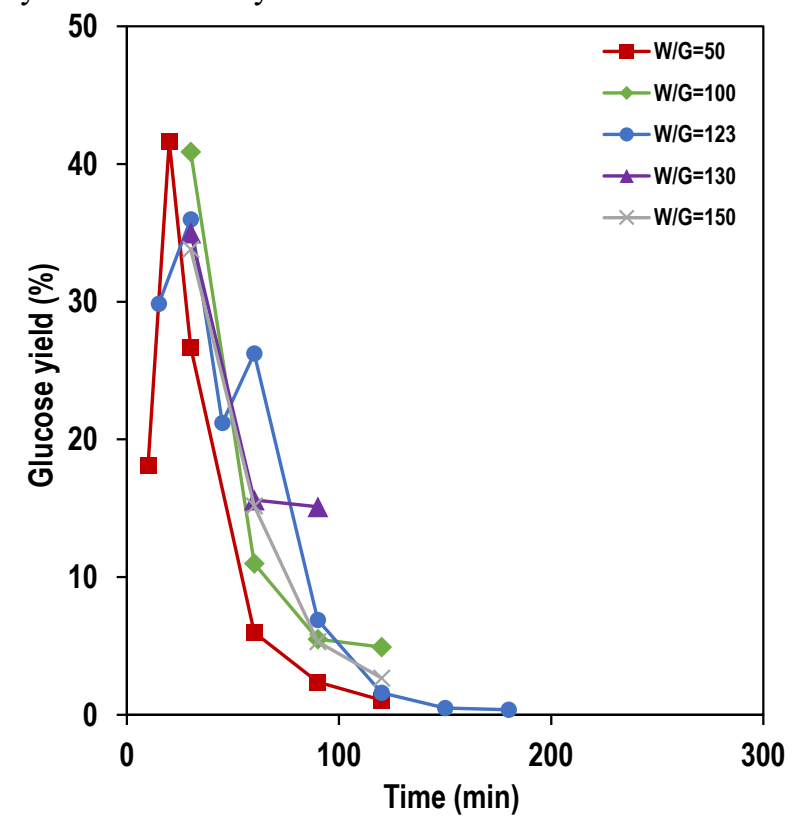

Figure 3 Time course of the glucose yield under various $\mathrm{W} / \mathrm{G}$ values using low molecular weight cellulose as a raw material $\left(200{ }^{\circ} \mathrm{C}\right)$

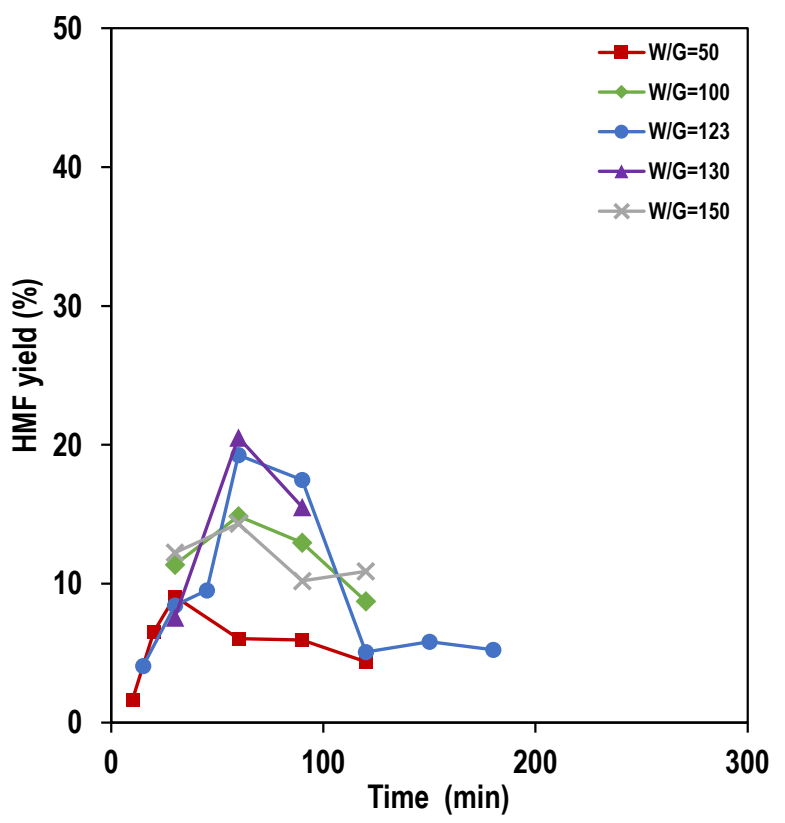

Figure 4 Time course of the HMF yield under various $\mathrm{W} / \mathrm{G}$ values using low molecular weight cellulose as a raw material $\left(200{ }^{\circ} \mathrm{C}\right)$ 


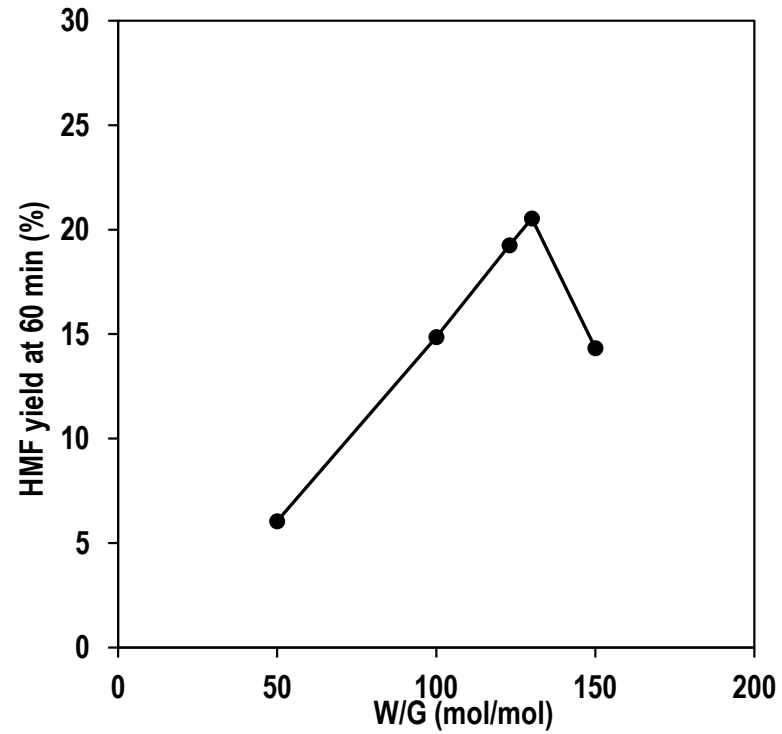

Figure 5 Relationship between the W/G value and HMF yield using low molecular weight cellulose as a raw material $\left(200^{\circ} \mathrm{C}\right)$

\section{Acknowledgements}

The authors received no specific funding for this work.

\section{References}

Binder, J. B. and R. T. Raines; "Simple Chemical Transformation of Lignocellulosic Biomass into Furans for Fuels and Chemicals," J. Am. Chem. Soc., 131, 19791985 (2009)

Kabyemela, B. M., T. Adschiri, R. M. Malaluan and K. Arai; "Kinetics of Glucose Epimerization and Decomposition in Subcritical and Supercritical Water," Ind. Eng. Chem. Res., 36, 1552-1558 (1997)

Kabyemela, B. M., T. Adschiri, R. M. Malaluan and K. Arai; "Glucose and Fructose Decomposition in Subcritical and Supercritical Water: Detailed Reaction Pathway, Mechanisms, and Kinetics," Ind. Eng. Chem. Res., 38, 2888-2895 (1999)

Kabyemela, B. M., M. Takigawa, T. Adschiri, R. M. Malaluan and K. Arai; "Mechanism and Kinetics of Cellobiose Decomposition in Sub- and Supercritical Water," Ind. Eng. Chem. Res., 37, 357-361 (1998)

Kim, B., J. Jeong, D. Lee, S. Kim, H.-J. Yoon, Y.-S. Lee and J. K. Cho; "Direct Transformation of Cellulose into 5-hydroxymethyl-2-furfural Using a Combination of Metal Chlorides in Imidazolium Ionic Liquid," Green Chem., 13, 1503-1506 (2011)

Peng, W.-H., Y.-Y. Lee, C. Wu and K. C. W. Wu; "Acidbase bi-functionalized, Large-Pored Mesoporous Silica Nanoparticles for Cooperative Catalysis of One-pot Cellulose-to-HMF Conversion," J. Mater. Chem., 22, 23181-23185 (2012)
Rosatella, A. A., S. P. Simeonov, R. F. M. Frade and C. A. M. Afonso; "5-Hydroxymethylfurfural (HMF) as a building block platform: Biological properties, synthesis and synthetic applications," Green Chem., 13(4), 754-793 (2011)

Shiraishi, K., T. Joboji and K. Taneda; "Method for solubilizing cellulose," US Patent US20140081013A1 (2014) 